\title{
Single Nucleotide Polymorphisms of the Alcohol Dehydrogenase Genes among the 28 Caste and Tribal Populations of India
}

\author{
B. M. Reddy ${ }^{1}$,A. N. S. Reddy ${ }^{1}$, T. Nagaraja ${ }^{1}$, L.V. K. S. Bhaskar ${ }^{2}$, K. Thangaraj ${ }^{2}$, \\ A. G. Reddy ${ }^{2}$ and L. Singh ${ }^{2}$

\section{Biological Anthropology Unit, Indian Statistical Institute, Hyderabad, Andhra Pradesh, India 2. Centre for Cellular and Molecular Biology, Hyderabad 500 007, Andhra Pradesh, India}

KEYWORDS ADH2 \& ADH3; Indian castes and tribes; social hierarchy; lifestyles; alcoholism

\begin{abstract}
We report single nucleotide polymorphisms (SNPs) at the four sites in ADH2 and ADH3 genes among the 28 populations from southern parts of Andhra Pradesh, India. A total of 1048 individuals belonging to 28 endogamous populations distributed in the contiguous areas of the 6 southernmost districts of Andhra Pradesh were enrolled for the present study. Genotyping involved PCR and sequencing. We sequenced exon 3 and 9 of $A D H 2$ and exon 8 of $A D H 3$, besides the ADH2 3'UTR- rs17033 (72 bases down stream of ADH2 Arg369Cys). The two sites of ADH2 (Arg47His and Arg369Cys) are found to be completely monomorphic showing only Arg47 and 369Arg $(\mathrm{ADH} 2 * 1$ allele), the remaining two sites were polymorphic. None of the 28 populations of this study deviated significantly from Hardy Weinberg Equilibrium proportions. The allele frequencies do not show any clear trend across socioeconomic groups. The degree of heterogeneity in the genotype frequencies among the hierarchical groups is significant for Ile349Val ( $\left.\mathrm{df}=12 ; \chi^{2}=22.050\right)$ and not for the $3^{\prime} \mathrm{UTR}$ rs17033 ( $\left.\mathrm{df}=6 ; \chi^{2}=9.765\right)$. The haplotype distribution among the hierarchical groups is found to be highly homogeneous and statistically nonsignificant $\left(\chi^{2}=\right.$ 0.248 , $\mathrm{df}=18$ ). Linkage disequilibrium does not exist between the two-polymorhic loci. The results were interpreted in the light of cultural patterns of the Indian hierarchical society.
\end{abstract}

\section{INTRODUCTION}

Alcohol dehydrogenase (ADH), a ratelimiting enzyme in alcohol metabolism, catalyzes the oxidation of ethanol to acetaldehyde. Alcohol dehydrogenase isoenzymes found in humans are unique, when compared with other animals. Seven ADH genes have been identified, characterized, and mapped to a gene cluster, located on chromosome 4 (Edenberg 2000). The different ADH isoenzymes have been classified based on enzymatic and DNA/protein sequence characteristics (Duester et al. 1999; Edenberg 2000). Genes for class I and IV ethanol oxidizing ADH have been well studied. The human system has additional complexity due to a gene triplication and polymorphism that occurs among the class I isoenzymes, giving rise to the following class I genes: $A D H 1, A D H 2 * 1, A D H 2 * 2$, $A D H 2 * 3, A D H 3 * 1$, and $A D H 3 * 2$. The protein products of these genes, previously named $\alpha$, $\beta 1, \beta 2, \beta 3, \gamma 1$ and $\gamma 2$, can form random associations to yield both homo and hetero-

Address for the Correspondence: Dr. B. Mohan Reddy, Ph.D. Professor, Biological Anthropology Unit Indian Statistical Institute, Street No. 8, Habsiguda Hyderabad 500 007, Andhra Pradesh, India Telephone: +91-40-27171906; Extn.:27

E-mail: bmr@isical.ac.in; bmrisi@gmail.com dimeric forms (Edenberg and Bosron 1997). These genes are approximately $15 \mathrm{~kb}$ in size with nine exons (Duester et al. 1986). No polymorphisms that affect enzyme activity have been described for the ADH1 gene, but the effects of diallelic amino acid substitutions within each of the $\mathrm{ADH} 2$ and $\mathrm{ADH} 3$ genes upon in vitro enzyme kinetics are well documented (Bosron et al. 1983; Edenberg and Bosron 1997). The ADH2*2 allele, consisting of the atypical $\beta 2$ subunit, exhibits about 100 times more catalytic activity for ethanol oxidation than the usual $\mathrm{ADH} 2 * 1 / * 1$ allele at physiological pH (Yoshida 1983). The ADH3*1 allele with a $\gamma 1$ subunit has a $V_{\max }$ about twice that of $\gamma 2$ encoded by ADH3*2 (Bosron et al. 1988). The kinetic properties of these genes led to a hypothesis for an etiological role in the development of problems associated with alcohol consumption (Shen et al. 1997; Whitfield 1997, Whitfield et al. 1998; Chen et al. 1999; Osier et al. 1999) because of their role in the metabolism of ingested alcohol.

A substantial variation in the frequency of allele $A D H 2 * 2(A D H 2 * 47 H i s)$, which protects from alcoholism, has been reported among the different ethnic groups. This allele codes for a protein with substitution Arg47 to His and, consequently, results in higher enzymatic activity (Osier et al. 2002; Whiteld 2002). ADH2 
genotypes, particularly the presence of an $\mathrm{ADH} 2 * 2$ allele, is related to differences in alcoholdrinking behaviour. Among Chinese living in Taiwan, the $\mathrm{ADH} 2 * 2$ allele was found to be substantially more common in the nonalcoholic group than in the alcoholics (Thomasson et al. 1991). Similar findings have been reported in the Atayal a native population of Taiwan (Thomasson et al. 1995), the Maori of New Zealand (Chambers et al. 2002), Spanish patients (Borras et al. 2000) and among Jews living in the USA or in Israel (Neumark et al. 1998). There was no apparent effect of ADH2 alleles on the quantity and frequency of drinking in Japanese men (Takeshita et al. 1994), although the number of individuals with the genotypes expected to predispose to the highest consumption (individuals homozygous for $\mathrm{ADH} 2 * 1$ ) is small because of the allele frequencies in this population. A more recent study however indicated that $\mathrm{ADH} 2 * 1$ was more common in heavy drinkers than in moderate drinkers (Tanaka et al. 1997). On the other hand, in Asians, the ADH $3 * 1$ allele was more prevalent in the nonalcoholics than in the alcoholics (Shen et al. 1997), but there is no apparent effect of the ADH3 locus on alcohol consumption or alcoholism rates in Caucasians (Gilder et al. 1993). However, the mechanism behind the protective effect of ADH3 gene is uncertain. Since the $\mathrm{ADH} 2 * 2$ allele encodes the highly active $\beta 2 \mathrm{ADH}$ isozyme, it has been postulated that faster conversion of alcohol to acetaldehyde could be 'protective' against heavy drinking and alcoholism, although alcohol elimination rates and peak blood acetaldehyde levels were not influenced by the ADH2*2 genotype (Mizoi et al. 1994). Fewer studies on the relationship between the ADH $2 * 3$ allele and risk of alcoholism or drinking behaviour have been carried out. The presence of ADH $2 * 3$ was associated with a negative family history of alcoholism (Ehlers et al. 2001) and with greater alcohol expectancies (Ehlers et al. 2003). However, the $\mathrm{ADH} 2 * 3$ allele was not found at a different frequency in alcoholics and controls in a study of more than 200 African-Americans (Taylor et al. 2003). The ADH3*1 allele is most prevalent among East Asians and Africans (about 90\%) and is about equally distributed with $\mathrm{ADH} 3 * 2$ in Caucasians (Agarwal and Goedde 1992). A critical evaluation of the earlier studies on the nature and extent of the association of the above polymorphisms with alcoholism, are far less conclusive for Caucasians because of the very low frequency of $A D H 2 * 2$ allele (Vidal et al. 2004). In addition, there is evidence that $A D H 2 * 2$ and $A D H 3 * 1$ alleles are in linkage disequilibrium (Chen et al. 1999; Osier et al. 1999), which clearly indicates that their contribution to the associated risk of alcoholism is not independent.

Pertinent to the Indian subcontinent, while Goedde et al. (1992) reported 9.9\% ADH2*2 allele in a heterogeneous sample of Indians, Osier et al. (2002) reported $6.6 \%$ of $\mathrm{ADH} 2 * 2$ allele in the Kachari population of Assam. These studies therefore cannot reflect the predominant pattern of distribution of $\mathrm{ADH}$ genes in the Indian subcontinent, which is contiguous to China and certain other Asian countries where some of these alleles show not only strong association with alcoholism but also high frequency of certain $\mathrm{ADH}$ alleles. In this paper, we report single nucleotide polymorphism at the 4 sites, three from the ADH2 (1B) and one from ADH3 (1C) genes among the 28 populations from southern parts of India. The studied populations represent almost entire gamut of socioeconomic and occupational variation inherent in the Indian population structure and are clearly stratified into upper, middle and lower castes and tribes. Since the traditional cultural and behavioral patterns of these populations pertaining to habitual drinking etc are known specific to each of them, we further endeavor to examine if the frequency of any of these alleles implicated in alcoholism follow a trend consistent with the known lifestyle patterns among them.

\section{MATERIALS AND METHODS}

A total of 1048 individuals belonging to 28 endogamous populations distributed in the contiguous areas of the 6 southernmost districts of Andhra Pradesh (Chittoor, Cuddapah, Ananthapur, Kurnool, Prakasam, and Nellore) (Fig.1) were included in the present study. All participants provided written informed consent and Review Committee of ISI, Kolkata, approved this study. Intravenous blood samples (about 5 $\mathrm{ml}$ each) were collected from them. The samples were drawn mostly from high school and college students, who represent a large number of surrounding villages and populations, and were supplemented with samples collected from the villages, particularly for tribes and lower castes. The names of the populations studied, the number 


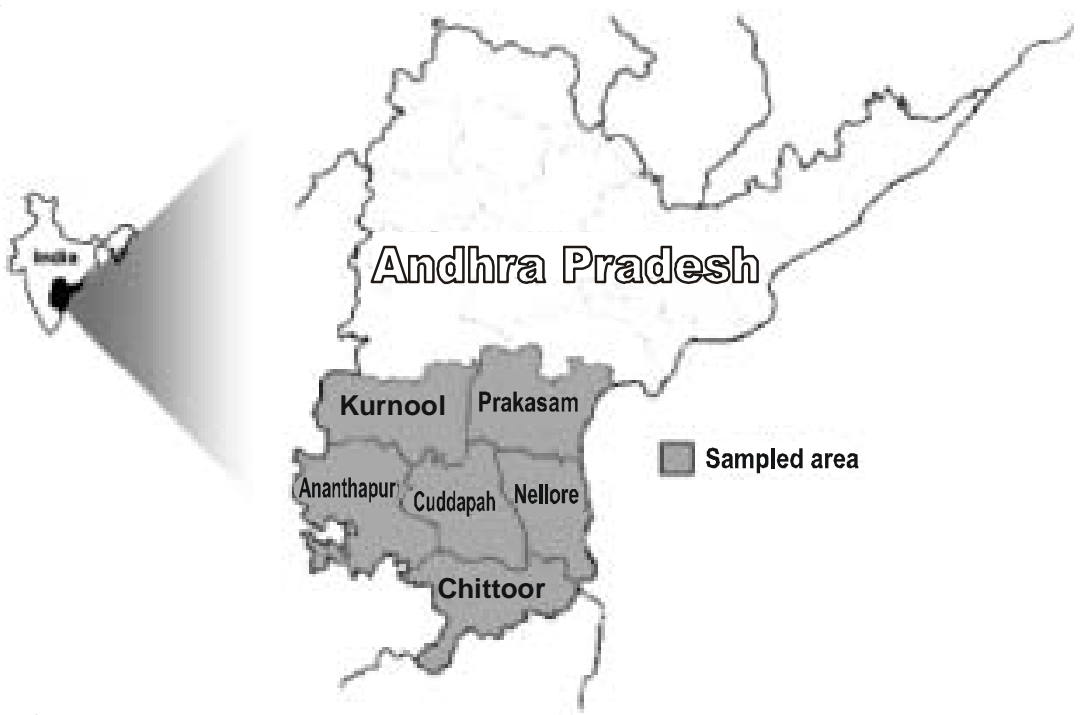

Populations: 1. Brahmin, 2. Kshatriya, 3. Vysya, 4. Akuthota, 5. Kamma, 6. Kapu, 7. Pokanati, 8. Panta , 9. Vanne 10. Balija, 11. Ekila, 12. Kurava, 13. Thogata 14. Yadava, 15. Ediga, 16. Gandla, 17. Jangam, 18. Devangapattur, 19. Chakali, 20. Mangali, 21. Vadde, 22. Madiga, 23. Mala, 24. Erukala, 25. Sugali, 26. Yanadi, 27. Dudekula, 28. Sheik

Fig. 1. Map of Andhra Pradesh showing sampled area and the name of populations studied.

of samples drawn from each population, and their socioeconomic backgrounds are furnished in Table 2. Although this study area can be considered culturally, linguistically, and geographically homogeneous, it is inhabited by a wide array of caste and tribal populations, representing almost the entire spectrum of socioeconomic variation in the state. DNA of the above samples was isolated from the peripheral lymphocytes by proteinase $\mathrm{K}$ (Sigma, USA) digestion followed by standard protocols with phenol-chloroform extraction and ethanol precipitation.

Genotyping of exon 3 and 9 of $A D H 2$ and exon 8 of $A D H 3$ (Table 1) involved PCR and sequencing. The PCR conditions and primers were as described earlier (Osier et al. 2002). PCR was carried out in a GeneAmp 9600 Thermal cycler (Perkin Elmer) in $10 \mu 1$ volume and using 1.0 U of AmpliTaq DNA polymerase (Applied Biosystems, Foster City, CA). PCR amplicons were checked on $2 \%$ agarose gel. PCR amplicons (70 ng) were directly sequenced using the BigDye Terminator Cycle Sequencing Kit ${ }^{\circledR}$ (Applied Biosystems, Foster City, CA) using 5PM primer (Thangaraj et al. 2003). Extended products were purified by alcohol precipitation followed by washing with $70 \%$ alcohol. Purified products were then dissolved in $10 \mu 1$ of $50 \% \mathrm{Hi}-\mathrm{Di}$ formamide and analysed in ABI3730 automated DNAAnalyser (Perkin Elmer, USA).

Statistical Analysis: Allele frequencies were computed using the Gene Counting method. Genotype distributions were tested for devia-tion from the Hardy-Weinberg Equilibrium proportions using the HWSIM program. To test the degree of heterogeneity in the genotype frequencies among the hierarchical groups $\chi^{2}$ tests were also performed. Haplotype and linkage disequilibrium analysis was performed using Arlequin software (Ver. 2.1).

Table 1: The description of the SNPs studied as part of ADH3 and ADH2 genes

\begin{tabular}{lcccc}
\hline SNP location & Relative position in gene & Polymorphic Site & Ancestral allele & db SNP ID \\
\hline ADH3 & Ile349Val & G/A TTTTA & G (Val) & rs698 \\
$\begin{array}{l}\text { Exon } 8 \\
\text { ADH2 }\end{array}$ & Arg47His & G/A CACAGA & G (Arg) & rs1229984 \\
Exon 3 & Arg369Cys & C/T GTACC & C (Arg) & rs2066702 \\
Exon 9 & - & A/G AGATCT & A & rs17033 \\
\hline 3'UTR & &
\end{tabular}




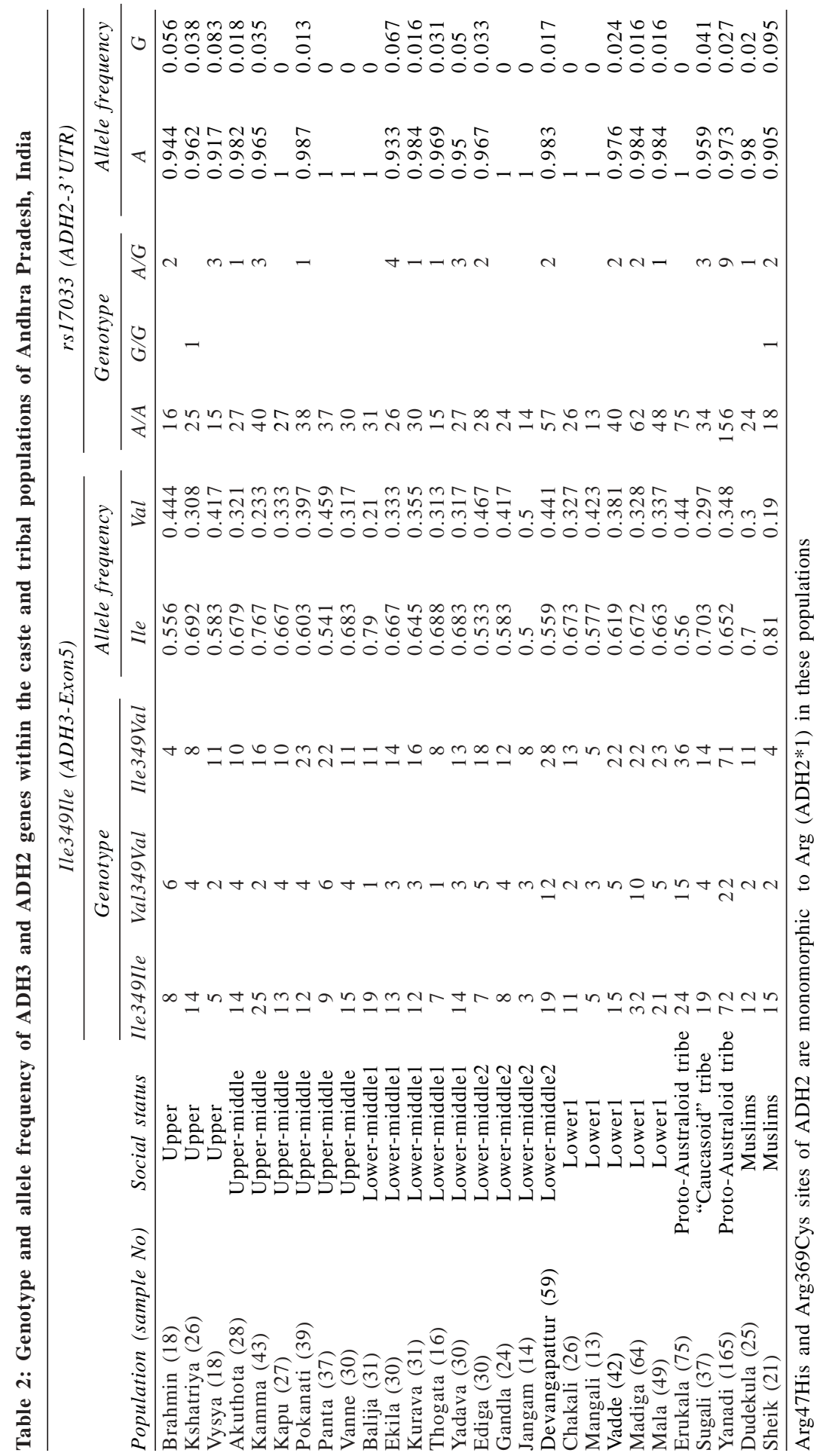




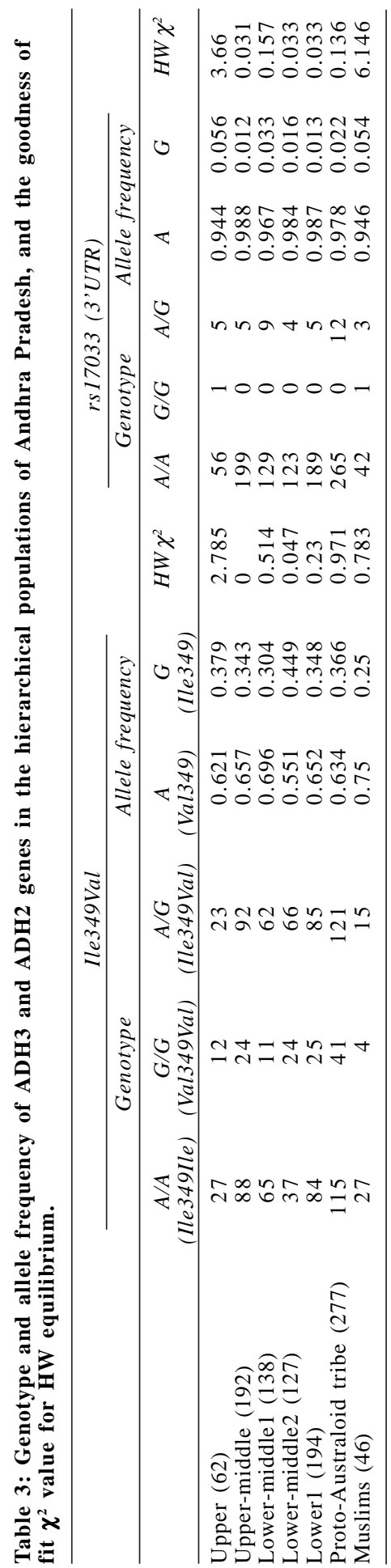

\section{RESULTS AND DISCUSSION}

At the protein level the allelic series for $\mathrm{ADH} 1 \mathrm{~B}(\mathrm{ADH} 2)$ is generated by variation at two different sites at the genomic level: $\mathrm{ADH} 2 * 1$ $(\mathrm{ADH} 1 \mathrm{~B} * 1)$ allele is composed of $47 \mathrm{Arg}$ and $369 \mathrm{Arg}, \mathrm{ADH} 2 * 2(\mathrm{ADHIB} * 2)$ allele is composed of $47 \mathrm{His}$ and $369 \mathrm{Arg}$ and $\mathrm{ADH} 2 * 3$ (ADHIB*3) allele is composed of $47 \mathrm{Arg}$ and $369 \mathrm{Cys}$. On the other hand, the two alleles for ADH3 (ADHIC) is generated by the substitution of isoleucin at 349 $(\mathrm{ADH} 3 * 1)$ to valine $(\mathrm{ADH} 3 * 2)$. Out of the 4 sites sequenced (Table 1) two (Arg47His \& Arg369Cys) were found to be totally absent in these populations, hence monomorphic for ADH2*1 (composing 47Arg and 369Arg). The $\mathrm{ADH} 2 * 2$ allele which is known to confer protection against alcoholism and found in high frequency in most East Asian populations was not found in any of the 28 populations that we screened for this study. The frequency of this allele $(A D H 2 * 2)$ was observed to be $>33 \%$ in East Asian populations and less than 25\% in other regions (Osier et al. 2002). Given the probable East Asian admixture, the frequency reported for Kacharis of Assam in India $(6.6 \%, N$ $=30)($ Osier et al. 2002) may be in order. As expected, the $A D H 2 * 3$ (ADH2*369Cys) which is essentially an African specific allele is also absent in the populations of the present study.

At the other two sites, which are polymorphic, none of the 28 populations of this study deviated significantly from Hardy Weinberg Equilibrium proportions after bonferroni correction (Table 2). At the $A D H 3^{*}$ Ile349Val site, the high activity allele $(A D H 3 * 1)$ is more frequent among these populations, ranging from 0.500 to 0.810 . However, ADH2 3'UTR- rs 17033 (72 bases down stream of ADH2 Arg369Cys) is polymorphic only in 19 of the 28 populations and the frequency of the derived allele $(\mathrm{G})$ range from 0 to $10 \%$. The degree of heterogeneity in the genotype frequencies among the hierarchical groups (Table 3 ) is significant for Ile $349 \mathrm{Val}\left(\mathrm{df}=12 ; \chi^{2}=22.050\right)$ and not for the 3'UTR rs17033 (df $\left.=6 ; \chi^{2}=9.765\right)$. However, the allele frequencies do not show any clear trend across socioeconomic groups. Out of 4 possible haplotypes constructed using the 4 sites (Fig. 2), AGCA is the major haplotype followed by GGCA, AGCG and GGCG. The distribution of these haplotypes among the hierarchical groups is found to be highly 


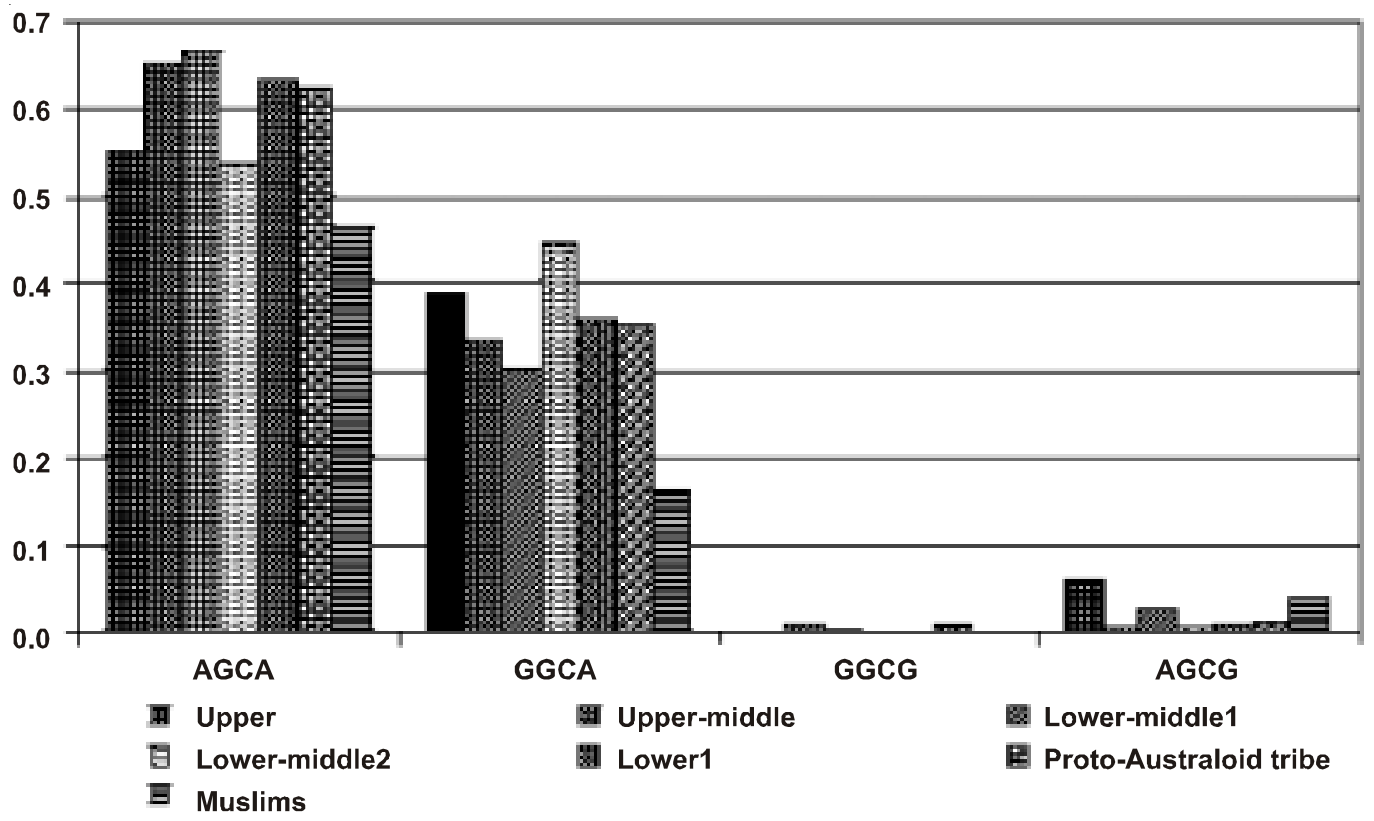

Fig. 2. Histogram depicting relative frequency of haplotypes based on the SNPs at the ADH3 and ADH2 genes. Given that two out of 4 sites are monomorphic, only four haplotypes are possible.

homogeneous and statistically nonsignificant $\left(\chi^{2}\right.$ $=0.248, \mathrm{df}=18)$. Linkage disequilibrium does not exist between the two-polymorhic loci.

While the complete absence of African specific $\mathrm{ADH} 2 * 3$ allele in the Indian populations is expected the total absence of $\mathrm{ADH} 2 * 2$ allele in these populations is somewhat intriguing given that it is found in the neighboring East Asian populations with high frequency and known to confer protection against alcoholism. Does this mean that this allele has no selective advantage/ role among the populations of India by way of preventing consumption of alcohol? Most traditional Indian populations that are particularly dependent on manual labor/intense physical activity are known to be habitual consumers of alcohol and these behavioral/lifestyle patterns have been well entrenched into the cultural patterns of the Indian hierarchical society so much so that the upper castes have traditional obligation to sponsor the members of service castes/lower castes for their expenses on drinking during certain religious occasions. Further, most of these populations in the lower rung of the Indian social system spend considerable amount of their earnings through hard physical labour on drinking. Therefore, the Indian populations might have developed genetic adaptation to withstand drinking unlike the most East Asian populations with known sensitivity to alcohol consumption, hence possibly requiring no protective mechanism, hence the $\mathrm{ADH} 2 * 2$ allele. It may be pertinent to recall that Carr et al. (2002) studying ADH2 polymorphisms in 4 groups of Jewish subjects in college age and in general population observed that college students consumed considerably more alcohol than the general population suggesting that social setting and age have a stronger influence on alcohol drinking than the effect of $\mathrm{ADH} 2 * 2$ allele.

Although ADH3*1 allele is observed in high frequency among these southern Indian populations, its association with alcoholism is said to be due to linkage disequilibrium with $\mathrm{ADH} 2 * 2$, rather than due to its direct role on the metabolic activity. Even so, given complete absence of $\mathrm{ADH} 2 * 2$ allele in these populations, hence monomorphic nature of $\mathrm{ADH} 2 * 1$, and in the absence of any pattern in $\mathrm{ADH} 3 * 1$ or $\mathrm{ADH} 3 * 2$ allele frequencies across hierarchical groups with known alcoholic consumption behaviors, no tangible interpretation can be 
deduced for the high frequency of this allele and its role in alcoholic behaviors. Nevertheless, our study may partly fill in the lacunae in the knowledge on the nature of distribution of ADH genes among the Indian populations.

\section{ACKNOWLEDGEMENTS}

This work is essentially a part of plan project of the Indian Statistical Institute (ISI), which is being carried out in collaboration with CCMB. BMR thanks Directors of both the institutes for logistic support, and the number of anonymous subject for their cooperation in giving blood samples.

\section{REFERENCES}

Agarwal DP, Goedde HW 1992. Pharmacogenetics of alcohol metabolism and alcoholism. Pharmacogenetics, 2: 48-62.

Borras E, Coutelle C, Rosell A, Fernandez-Muixi F, Broch M, Crosas B, Hjelmqvist L, Lorenzo A, Gutierrez C, Santos M, Szczepanek M, Heilig M, Quattrocchi P, Farres J, Vidal F, Richart C, Mach T, Bogdal J, Jornvall H, Seitz HK, Couzigou P, Pares X 2000. Genetic polymorphism of alcohol dehydrogenase in europeans: the $\mathrm{ADH} 2 * 2$ allele decreases the risk for alcoholism and is associated with $\mathrm{ADH} 3 * 1$. Hepatology, 31: 984-989.

Bosron WF, Lumeng L, Li TK 1998. Genetic polymorphism of enzymes of alcohol metabolism and susceptibility to alcoholic liver disease. Mol Aspects Med, 10:147-58.

Bosron WF, Magnes LJ, Li TK 1983. Human liver alcohol dehydrogenase: ADH Indianapolis results from genetic polymorphism at the ADH2 gene locus. Biochem Genet, 21: 735-744.

Carr LGC, Foroud T, Stewart T, Castelluccio P, Edenberg $\mathrm{HJ}, \mathrm{Li} \mathrm{TK}$ 2002. Influence of ADH1B polymorphism on alcohol use and its subjective effects in a Jewish population. Am J Med Genet, 112: $138-143$.

Chambers GK, Marshall SJ, Robinson GM, Maguire S, Newton HJ, Chong NL 2002. The Genetics of Alcoholism in Polynesians: Alcohol and Aldehyde Dehydrogenase Genotypes in Young Men. Alcohol Clin Exp Res, 26: 949-955.

Chen YC, Lu RB, Peng GS, Wang MF, Wang HK, Ko HC, Chang YC, Lu JJ, Li TK, Yin SJ 1999. Alcohol metabolism and cardiovascular response in an alcoholic patient homozygous for the ALDH2*2 variant gene allele. Alcohol Clin Exp Res 23: 18531860.

Duester G, Farres J, Felder MR, Holmes RS, Hoog JO, Pares X, Plapp BV, Yin SJ, Jornvall H 1999. Recommended nomenclature for the vertebrate alcohol dehydrogenase gene family. Biochem Pharmacol, 58: 389-395.

Duester G, Smith M, Bilanchone V, Hatfield GW 1986. Molecular analysis of the human class I alcohol dehydrogenase gene family and nucleotide sequence of the gene encoding the beta subunit. J Biol Chem, 261: 2027-2033.

Edenberg HJ, Bosron WF 1997. Alcohol dehydrogenases. pp 119-131. In: FP Guengerich (Ed) Comprehensive Toxicology. Vol 3: Biotransformation. New York: Pergamon Press.

Edenberg HJ 2000. Regulation of the mammalian alcohol dehydrogenase genes. Prog Nucleic Acids Res Molec Biol, 64: 295-341.

Ehlers CL, Gilder DA, Harris L, Carr L 2001. Association of the $\mathrm{ADH} 2 * 3$ allele with a negative family history of alcoholism in African American young adults. Alcohol Clin Exp Res, 25:1773-1777.

Ehlers CL, Phillips E, Sweeny A, Slawecki CJ 2003. Event-related potential responses to alcohol-related stimuli in African-American young adults: Relation to family history of alcoholism and drug usage. Alcohol Alcohol, 38:332-338.

Gilder FJ, Hodgkinson S, Murray RM 1993. ADH and ALDH genotype profiles in Caucasians with alcohol-related problems and controls. Addiction, 88: 383-388.

Goedde HW, Agarwal DP, Fritze G, Meier-Tackmann D, Singh S, Beckmann G, Bhatia K, Chen LZ, Fang B, Lisker R, Paik YK, Rothhammer F, Saha N, Segal B, Srivastava LM, Czeizel A 1992. Distribution of $\mathrm{ADH}-2$ and ALDH2 genotypes in different populations. Hum Genet, 88: 344-346.

Mizoi Y, Yamamoto K, Ueno Y, Fukunaga T, Harada S 1994. Involvement of genetic polymorphism of alcohol and aldehyde dehydrogenases in individual variation of alcohol metabolism. Alcohol Alcohol, 29: 707-710.

Neumark YD, Friedlander Y, Thomasson HR, Li T-K 1998. Association of the ADH2*2 allele with reduced ethanol consumption in Jewish men in Israel: A pilot study. J Stud Alcohol, 59: 133139.

Osier MV, Pakstis AJ, Soodyall H, Comas D, Goldman D, Odunsi A, Okonofua F, Parnas J, Schulz LO, Bertranpetit J, Bonne-Tamir B, Lu RB, Kidd JR, Kidd KK 2002. A global perspective on genetic variation at the $\mathrm{ADH}$ genes reveals unusual patterns of linkage disequilibrium and diversity. Am J Hum Genet, 71: 84-99.

Osier MV, Pakstis AJ, Kidd JR, Lee JF, Yin SJ, Ko HC, Edenberg HJ, Lu RB, Kidd KK 1999. Linkage disequilibrium at the $\mathrm{ADH} 2$ and $\mathrm{ADH} 3$ loci and risk of alcoholism. Am J Hum Genet, 64: 1147-1157.

Shen YC, Fan JH, Edenberg HJ, Li TK, Cui YH, Wang YF, Tian CH, Zhou CF, Zhou RL, Wang J, Zhao ZL, Xia GY 1997. Polymorphism of ADH and ALDH genes among four ethnic groups in China and effects upon the risk for alcoholism. Alcohol Clin Exp Res, 21: $1272-1277$.

Takeshita T, Mao XQ, Morimoto K 1996. The contribution of polymorphism in the alcohol dehydrogenase beta subunit to alcohol sensitivity in a Japanese population. Hum Genet, 97: 409-413.

Tanaka F, Shiratori Y, Yokosuka O, Imazeki F, Tsukada Y, Omata M 1997. Polymorphism of alcoholmetabolizing genes affects drinking behavior and alcoholic liver disease in Japanese men. Alcohol Clin Exp Res, 21: 596-601.

Taylor RE, Flury L, Scott DM, Foround T, Kalu N, Bland W, Li TK, Carr LG 2003. Allele frequencies 
of $\mathrm{ADH} 2$ and $\mathrm{ADH} 3$ polymorphism among various ethnic groups. Alcohol Clin Exp Res, 27, S8Abstr. Thangaraj K, Joshi MB, Reddy AG, Rasalkar AA, Singh L 2003. Sperm mitochondrial mutations as a cause of low sperm motility. J Androl, 24: 388-392.

Thomasson HR, Beard JD, Li TK 1995. ADH2 gene polymorphisms are determinants of alcohol pharmacokinetics. Alcohol Clin Exp Res, 19: 14941499.

Thomasson HR, Edenberg HJ, Crabb DW, Mai XL, Jerome RE, Li TK, Wang SP, Lin YT, Lu RB, Yin SJ 1991. Alcohol and aldehyde dehydrogenase genotypes and alcoholism in Chinese men. Am J Hum Genet, 48: 677-681.

Vidal F, Lorenzo A, Auguet T, Olona M, Broch M, Gutierrez C, Aguilar C, Estupina P, Santos M, Richart C 2004. Genetic polymorphisms of ADH2, ADH3, CYP4502E1 Dra-I and Pst-I, and ALDH2 in Spanish men: lack of association with alcoholism and alcoholic liver disease. J Hepatol, 41: 744-750.

Whitfield JB, Nightingale BN, Bucholz KK, Madden PA, Heath AC, Martin NG 1998. ADH genotypes and alcohol use and dependence in Europeans. Alcohol Clin Exp Res, 22: 1463-1469.

Whitfield JB1997. Meta-analysis of the effects of alcohol dehydrogenase genotype on alcohol dependence and alcoholic liver disease. Alcohol Alcohol, 32: 613619.

Whitfield JB 2002. Alcohol dehydrogenase and alcohol dependence: variation in genotype-associated risk between populations. (Letter) Am J Hum Genet, 71: $1247-1250$.

Yoshida A 1983. Differences in the isozymes involved in alcohol metabolism between caucasians and orientals. Isozymes Curr Top Biol Med Res, 8: 245-261. 